\section{CDK8 is enough in colorectal cancer}

\section{ByLev Osherovich, Senior Writer}

Of the 11 known cyclin-dependent kinases, about half have long been the focus of cancer drug developers because they are involved in controlling cell-cycle progression, which goes into overdrive in cancer. However, none of the companies developing cyclin-dependent kinase inhibitors for cancer is specifically targeting cyclin-dependent kinase 8 , a kinase that has been considered a player in transcription initiation but with minimal effects on the cell cycle.

Now, two papers in Nature outline how cyclin-dependent kinase 8 (CDK8) controls a critical pathway in colorectal cancer that is unrelated to cell-cycle control. ${ }^{1,2}$ The findings open a new angle of attack that is downstream of epidermal growth factor receptor (EGFR), a target of approved antibodies against the cancer. Companies in the space now have good cause to re-examine CDK8 as a target,

"Colorectal cancer cells
seem to select for multiple
features that collectively
enhance the activity of
B-catenin." - Nicholas Dyson,
Massachusetts General Hospital

"Colorectal cancer cells seem to select for multiple features that collectively enhance the activity of catenin-driven reporter gene. In the other screen, CDK8 knockdown slowed proliferation of $\beta$-catenin-dependent colorectal tumor cells.

Although eight other genes also showed overlap, the team focused on $\mathrm{CDK} 8$ because of previous research showing that the chromosomal region containing CDK8 was amplified in many colon tumors. ${ }^{3,4}$ Hahn's team found extra copies of a chromosomal region encompassing the CDK8 gene in 58 of 123 colon cancer patient samples.

His group showed that RNAi knockdown of CDK8 - but not of neighboring genes in the amplified chromosomal region-slowed tumor cell growth. This suggested that overexpression of CDK8 was sufficient for aggressive growth of these tumor cells.

To confirm this hypothesis, the researchers overexpressed CDK8 in an untransformed cell line and saw more anchorage-independent growth, a hallmark of aggressive tumor cells, than that seen in mocktreated controls.

Hahn thinks CDK8's key role in colon cancer is to boost the expression of $\beta$-catenin target genes. For example, the team found that in cultured colorectal cancer cells, CDK8 interacted with the promoter of $c$ $M y c$, a well-studied $\beta$-catenin target gene that promotes tumor growth. Conversely, CDK8 knockdown lowered transcription of $c$-Myc and other $\beta$-catenin target genes compared with that seen in mock-treated controls.

Hahn told SciBX that his team is making a transgenic mouse model of CDK8 overexpression. although this new role may require new compound-screening strategies and in vivo assays.

The studies were conducted by two independent groups at separate institutes associated with Harvard Medical School.

One team, led by William Hahn, associate professor of medicine at Dana-Farber Cancer Institute, came across CDK8 through RNAi knockdown screens for colon cancer cell proliferation genes. The other team, led by Nicholas Dyson, professor of medicine at the Massachusetts General Hospital Cancer Center, used Drosophila and human cell cultures to uncover how CDK8 blocks E2F transcription factor 1 (E2F1), a transcription factor that curbs tumor growth.

Together, the studies show that CDK8 activates a pathway involving $\beta$-catenin, a transcription factor that drives the growth of most colon tumors.

"We've known for many years that the $\beta$-catenin pathway is active in a majority of tumors, but given that it's a transcription factor, it's been difficult to come up with drugs that target the pathway," said Hahn. In contrast, he said, "CDK8 is a kinase, a druggable class of protein."

\section{Going CDK fishing}

Hahn's team came across CDK8 by looking for overlapping hits in two separate screens of a human kinase RNAi library-one screen looked at transcriptional activity and the other looked at tumor growth. In the first screen, knockdown of CDK8 prevented the expression of a $\beta$ -
The team is also screening other tumor cell lines using the double RNAi approach to identify genes with functions that are similar to CDK8.

\section{In the wings}

Meanwhile, Dyson's team independently identified CDK8's role in colorectal cancer in a genetic study of E2F1 activity in fly wing and eye development, a model of $\beta$-catenin activation.

Overexpression of E2F1 promotes apoptosis, causing fly wings to appear gnarled compared with those of wild-type controls. Dyson's team found simultaneous overexpression of $\beta$-catenin along with E2F1 restored the normal appearance of fly wings, suggesting that the two transcription factors interact genetically to produce opposing effects.

Dyson's team then sought to identify genes that influence the genetic interactions between E2F1 and $\beta$-catenin. Among these genes were CDK8 and several other members of a protein complex called Mediator, which aids transcription initiation. For example, the team found that lower levels of CDK8 activity corrected the rough appearance of fly eyes expressing an E2F1 knockdown construct.

Dyson's group concluded that CDK8 and other Mediator proteins antagonized E2F1, thus increasing $\beta$-catenin's activity. This hypothesis was borne out by transcription activation and coimmunoprecipitation experiments in $\beta$-catenin-driven colorectal cancer cell lines that essentially recapitulated the Dana-Farber team's findings.

Dyson told SciBX that the concordance between his and Hahn's 


\section{TARGETS \& MECHANISMS}

Table 1. Targeting CDKs. Selected compounds targeting cyclin-dependent kinases (CDKs) in clinical development.

\begin{tabular}{|c|c|c|c|c|}
\hline Company & Product & Description & Indication & Status \\
\hline $\begin{array}{l}\text { sanofi-aventis Group } \\
\text { (Euronext:SAN; NYSE:SNY) }\end{array}$ & Alvocidib (HMR1275) & CDK inhibitor & $\begin{array}{l}\text { Chronic lymphocytic } \\
\text { leukemia (CLL) }\end{array}$ & Phase II/III \\
\hline $\begin{array}{l}\text { Cyclacel Pharmaceuticals } \\
\text { Inc. (NASDAQ:CYCC) }\end{array}$ & Seliciclib (CYC202) & $\begin{array}{l}\text { Inhibitor of CDK2E, } \\
\text { CDK2A, CDK7 and CDK9 }\end{array}$ & $\begin{array}{l}\text { Non-small cell lung cancer } \\
\text { (NSCLC); nasopharyngeal } \\
\text { cancer }\end{array}$ & Phase II \\
\hline $\begin{array}{l}\text { Eisai Co. Ltd. (Tokyo:4523; } \\
\text { Osaka:4523) }\end{array}$ & Indisulam (E7070) & $\begin{array}{l}\text { Synthetic sulfonamide } \\
\text { compound that indirectly } \\
\text { inhibits CDK activity }\end{array}$ & Cancer & Phase II \\
\hline $\begin{array}{l}\text { Kyowa Hakko Kogyo Ltd. } \\
\text { (Tokyo:4151) }\end{array}$ & UCN-01 & $\begin{array}{l}\text { 7-hydroxystaurosporine } \\
\text { compound that indirectly } \\
\text { inhibits CDK activity }\end{array}$ & Cancer & Phase II \\
\hline Astex Therapeutics Ltd. & AT7519 $^{A}$ & $\begin{array}{l}\text { Inhibitor of several CDKs, } \\
\text { including CDK1, CDK2 and } \\
\text { CDK9 }\end{array}$ & Cancer & Phase I \\
\hline Pfizer Inc. (NYSE:PFE) & PD $332991^{\mathrm{B}}$ & CDK4 inhibitor & Cancer & Phase I \\
\hline $\begin{array}{l}\text { Sunesis Pharmaceuticals } \\
\text { Inc. (NASDAQ:SNSS) }\end{array}$ & SNS- $032^{\mathrm{C}}$ & $\begin{array}{l}\text { Inhibitor of CDK2, CDK7 } \\
\text { and CDK9 }\end{array}$ & $\begin{array}{l}\text { CLL; multiple myeloma } \\
(\mathrm{MM})\end{array}$ & Phase I \\
\hline Roche (SWX:ROG) & R547 & $\begin{array}{l}\text { Inhibitor of CDK1, CDK2, } \\
\text { CDK4, CDK7 and CDK9 }\end{array}$ & Cancer & Phase I \\
\hline
\end{tabular}

findings points to the critical role of CDK8 in controlling tumor growth.

"Colorectal cancer cells seem to select for multiple features that collectively enhance the activity of $\beta$-catenin," said Dyson. Among these features are overexpression of CDK8, which leads to inhibition of E2F1, he added.

Dyson next plans to examine the effect of E2F1 inhibition in a mouse model of colorectal cancer and to identify tumor subtypes that are more sensitive to E2F1 deregulation.

Neither Hahn nor Dyson have sought patents for their discoveries.

\section{Coming full cycle}

At least eight companies have CDK inhibitors in clinical development for various cancers (see Table 1, “Targeting CDKs"). The challenge with the targets, said Spiro Rombotis, CEO of Cyclacel Pharmaceuticals Inc., is inhibiting the correct CDKs at the right time.

CDKs interact with cofactors called cyclins, whose levels typically rise and fall throughout the cell cycle. This leads to periodic oscillation of CDK activity, a process that keeps the various steps of cell division in sync.

In contrast, levels of CDK8's partner-cyclin C-remain constant throughout the cell cycle. Thus, CDK8 activity does not fluctuate, which may have led to the relative neglect of that kinase in cell cycle-centric approaches to cancer research.

However, Rombotis said the two Harvard studies reinforce a growing view that beyond controlling cell-cycle progression, CDKs play a second role in tumor-associated transcriptional activation. The studies suggest that inhibition of CDK8 promotes apoptosis-the goal of many cancer drugs-independently of cell cycle-related processes.

Cyclacel's seliciclib, a CDK inhibitor of CDK2, CDK7 and CDK9, is in Phase II trials for non-small cell lung cancer (NSCLC) and metastatic nasopharyngeal cancer.
Rombotis emphasized that targeting CDK8 should be part of a broader strategy of inhibiting multiple CDKs.

"After 15 years of research in this area, we have learned that these enzymes have to be inhibited in groups," he said. "Although CDK8 appears to be a promising target, a single CDK enzyme-selective compound is unlikely to be effective in cancers induced by multiple mutations."

Rombotis also noted that Dyson's identification of CDK8 as an antagonist of E2F1 widens the range of cancer pathways for which CDK inhibitors could be useful. Previous work had connected E2F1 to the retinoblastoma 1 (RB1) tumor suppressor pathway, which goes awry in multiple cancers.

ArQule Inc. and Celleron Therapeutics Ltd. are targeting E2F1 with their respective preclinical compounds.

Nick LaThangue, CEO of Celleron and professor of oncology at University of Oxford, thinks the Nature papers strengthen the case for his company's CT300, which aims to stimulate E2F1 activity to treat various cancers.

"It is generally accepted that if you were to activate E2F1 to a sufficient level in tumor cells, you would induce apoptosis," he said. However, until the discovery of enzymes that aberrantly inhibit E2F1 in cancer, "nobody's understood how to activate it."

Inhibiting E2F1 inhibitors, which include CDK8, RB1 and an undisclosed methyltransferase targeted by CT300, would have the effect of increasing E2F1 activity and thus promoting tumor cell apoptosis.

"On the face of it, CDK8 appears to be a good target" to achieve this goal, said LaThangue.

However, he cautioned that targeting CDKs has proven difficult because of their ubiquitous roles in cell-cycle control and transcription, together with the lack of sufficiently selective small molecule inhibitors. In contrast, therapies that target other E2F1 inhibitors may preferentially affect tumor cells over normal tissue.

CT300 is in preclinical development for colorectal cancer and other 


\section{TARGETS \& MECHANISMS}

undisclosed cancer indications. LaThangue expects the compound to enter Phase I trials in early 2010.

Rombotis did say that CDK8's presumed cyclin-independent role in tumor development could pose problems in drug development. Conventional cell cycle-related screening methods use cell cycle-related readouts, such as fluorescent-activated cell sorting analysis and nuclear DNA content.

Even if good in vitro CDK8 inhibitors can be found, the cyclin-independent effects of the kinase may complicate the interpretation of in vivo data. "We don't have a sophisticated in vivo readout [...] to learn what effect inhibiting CDK8 might have," said Rombotis.

The extra effort could be worth it, however, given that Hahn's Nature article suggests that almost $50 \%$ of colorectal cancers may be dependent on the CDK8-controlled pathway.

By comparison, the efficacy of the marketed anti-EGFR antibodies for the disease-Vectibix panitumumab from Amgen Inc. and Erbitux cetuximab from ImClone Systems Inc., Bristol-Myers Squibb Co. and Merck $\mathbf{K G a A}$-is restricted to Kras wild-type patients. In that subpopulation, which is about $60 \%$ of the total colorectal cancer population, the response rate to the drugs is about $15 \%$.

Vectibix and Erbitux posted 1H08 U.S. sales of $\$ 57$ million and
$\$ 378$ million, respectively. EGFR is a kinase that acts far upstream of CDK8.

\section{REFERENCES}

1. Firestein, R. et al. Nature; published online Sept. 14, 2008; doi:10.1038/nature07179

Contact: William Hahn, Dana-Farber Cancer Institute, Boston, Mass. e-mail: william_hahn@dfci.harvard.edu

2. Morris, E.J. et al. Nature; published online Sept. 14, 2008; doi:10.1038/nature07310

Contact: Nicholas J. Dyson, Harvard Medical School, Charlestown, Mass. e-mail: dyson@helix.mgh.harvard.edu

3. Martin, E.S. et al. Cancer Res. 67, 10736-10743 (2007)

4. Tsafrir, D. et al. Cancer Res. 66, 2129-2137 (2006)

COMPANIES AND INSTITUTIONS MENTIONED

Amgen Inc. (NASDAQ:AMGN), Thousand Oaks, Calif. ArQule Inc. (NASDAQ:ARQL), Woburn, Mass.

Bristol-Myers Squibb Co. (NYSE:BMY), New York, N.Y.

Celleron Therapeutics Ltd., Oxford, U.K.

Cyclacel Pharmaceuticals Inc. (NASDAQ:CYCC), Berkeley Heights, N.J. Dana-Farber Cancer Institute, Boston, Mass.

Harvard Medical School, Boston, Mass.

ImClone Systems Inc. (NASDAQ:IMCL), New York, N.Y.

Massachusetts General Hospital, Boston, Mass.

Merck KGaA (Xetra:MRK), Darmstadt, Germany

University of Oxford, Oxford, U.K. 